\title{
Evaluation of Heavy Metal Pollution in Shallow Groundwater of Farmland in Huaibei Plain, China
}

\author{
Yong Zhang ${ }^{1 *}$, Xuanxia Wang ${ }^{1}$ \\ ${ }^{1}$ School of Environment and Surveying Engineering, Suzhou University, Suzhou City, Anhui Province, 234000, China
}

\begin{abstract}
In order to understand the characteristics of heavy metal pollution in shallow groundwater in farmland in Huaibei Plain, 69 samples were collected from typical farmland areas in Xiaoxian County to determine the content of heavy metal elements such as $\mathrm{Cr}, \mathrm{Zn}, \mathrm{Cu}, \mathrm{Cd}$, and Ni. The single-factor pollution index method and Nemerow comprehensive index method are used to evaluate and analyze the pollution degree and the health risk assessment method is used to explore the health risk level. The results show that the concentrations of $\mathrm{Cr}, \mathrm{Zn}, \mathrm{Cu}, \mathrm{Cd}$ and $\mathrm{Ni}$ were respectively $1.27 \mu \mathrm{g} \cdot \mathrm{L}^{-1} \sim 268.78 \mu \mathrm{g} \cdot \mathrm{L}^{-1}, 0.45 \mu \mathrm{g} \cdot \mathrm{L}^{-1} \sim$ $266.1 \mu \mathrm{g} \cdot \mathrm{L}^{-1}, 1.77 \mu \mathrm{g} \cdot \mathrm{L}^{-1} \sim 29.8 \mu \mathrm{g} \cdot \mathrm{L}^{-1}, 0.10 \mu \mathrm{g} \cdot \mathrm{L}^{-1} \sim 21.54 \mu \mathrm{g} \cdot \mathrm{L}^{-1}$ and $0.9 \mu \mathrm{g} \cdot \mathrm{L}^{-1} \sim 252.85 \mu \mathrm{g} \cdot \mathrm{L}^{-1}$. The Nemerow comprehensive index of each heavy metal element is 0.031 5.507, and the pollution degree is $\mathrm{Ni}>\mathrm{Cr}>\mathrm{Cd}>\mathrm{Zn}>\mathrm{Cu}$. The Nemerow comprehensive pollution index of each sampling point is 0.251 9.325, with an average value of 1.934 . The overall value is 9.523 , and the pollution level is extremely poor. The overall health risk is at a risk-free health level. There are 19 samples which the carcinogenic risk index of the $\mathrm{Cr}$ is greater than $10^{-4}$, and the number of samples with health risks accounts for $27.5 \%$. $\mathrm{Cr}$ is the main source of heavy metal health risks in shallow groundwater in farmland.
\end{abstract}

\section{Introduction}

Groundwater is an important source of water for human life, as well as an important source of water for agricultural production. With the continuous development of human society and economy, human activities have brought serious pollution to water resources $^{[1]}$. Surface water is threatened by humans, and groundwater is also being polluted, especially heavy metal pollution. At the same time, due to surface water replenishment, infiltration or leaching, heavy metals in surface water will also be brought to shallow groundwater ${ }^{[2]}$. Most of the heavy metals are carcinogenic. Once too many heavy metals enter the water body, it will directly or indirectly affect the health of the human body, and even seriously affect the aquatic ecosystem $^{[3]}$. When the accumulated heavy metal content in the human body exceeds the tolerable level, the normal physiological functions of the human body will be interfered, which will cause varying degrees of harm to the important functional organs of the human body, and may even threaten human life safety. Heavy metal pollution in shallow groundwater of farmland is a representative research direction of heavy metal pollution in groundwater, which mainly comes from the accumulation of chemical fertilizers, farm manure (poultry manure) and pesticides used in farming and planting in the soil ${ }^{[4]}$, which can be used in the food chain. Accumulation in farmland crops leads to excessive heavy metal content in crops and causes

\footnotetext{
*Corresponding author's e-mail: zhangyong@ahszu.edu.cn
}

human health risks. Investigation and research on the status quo is of great significance for its treatment and timely restoration.

At present, many scholars and experts conduct research and analysis on the heavy metal pollution of water bodies, and put forward feasibility suggestions. Sun Jianxiong ${ }^{[5]}$ and others used principal component analysis and correlation analysis to analyze the sources of heavy metals in surface waters in the coastal area of Yancheng, Jiangsu, and used the comprehensive pollution index method to evaluate heavy metal pollution; Yang Xuefu ${ }^{[6]}$ and others used single-factor water quality Standard comparison method, heavy metal pollution index method and health risk assessment method are used to evaluate and analyze heavy metal pollution in water bodies and health risks. This study focuses on the heavy metal pollution of shallow groundwater in farmland in the Huaibei Plain, and evaluates the degree of heavy metal pollution and health risks, which can provide technical support for the current status of regional water environmental quality.

\section{Materials and Methods}

\subsection{Overview of the study area}

Xiaoxian County is located in the northern part of Anhui Province, at the intersection of Jiangsu Province, Shandong Province, Henan Province and Anhui Province. It covers an area of $1885.30 \mathrm{~km}^{2}$, accounting 
for about $1.3 \%$ of the total area of Anhui Province. Generally speaking, the terrain is relatively flat. Most of them are plains. Due to the influence and control of the monsoon climate in Xiaoxian County, summer rainfall is relatively concentrated, and precipitation is relatively large; winter precipitation is relatively small, and the dry and wet seasons are distinct. According to statistics, the maximum annual precipitation in Xiaoxian County is $1320.3 \mathrm{~mm}$; the minimum annual precipitation is $562.5 \mathrm{~mm}$, and the annual average precipitation is $854.6 \mathrm{~mm}$.

The climatic conditions in Xiaoxian County determine the direction of agricultural development as dry farming, and its main crops are wheat, corn and soybeans. In 2017, Xiaoxian's annual total grain output was 771,100 tons, the sown area was about 16 hectares, and the total output value was 534 million yuan. Groundwater is the main source of irrigation water for farmland in Xiaoxian County, as well as the main source of drinking water. According to the 2017 Xiaoxian County Environmental Quality Report, the water quality of centralized drinking water sources meets the requirements of Class III water in the groundwater quality standards.

\subsection{Samples collection and analysis}

Select typical farmland irrigation wells from representative villages and towns in Xiaoxian County as sample collection points, store 69 water samples collected in clean bottles in 2019 , and send the samples back to the school laboratory for determination after pretreatment. Strictly follow Relevant operating specifications. According to relevant national testing methods and requirements, graphite furnace atomic absorption spectrometry and flame atomic absorption spectrometry are used to determine the concentration of $\mathrm{Cr}, \mathrm{Cu}, \mathrm{Zn}, \mathrm{Cd}$, and $\mathrm{Ni}$ in water samples. Each sample needs to be measured three times. The average of the measured values is used as the final result of this research, and deionized water should be used as a blank sample for comparison during the detection process.

\subsection{Evaluation method}

\subsubsection{Single factor pollution index method}

The single-factor pollution index method is an evaluation method based on the environmental quality standards used by pollutants. Its advantage is simple operation and easy implementation; but it is only used to reflect the pollution degree of each heavy metal element in the sampling point. And cannot reflect the overall pollution level caused by the combination of multiple pollution factors ${ }^{[7]}$. See formula (1) for calculation.

$$
\mathrm{Pi}=\mathrm{Ci} / \mathrm{Si}
$$

Pi represents the single factor index of heavy metal element $\mathrm{i}$ in groundwater; $\mathrm{Ci}$ represents the actual measured concentration of heavy metal $i$ in groundwater, and $\mathrm{Si}$ refers to the evaluation standard value used for heavy metals in groundwater. The grading standard of single factor pollution index is shown in Table 1.

Table 1. Single-factor pollution index grading standards

\begin{tabular}{ccc}
\hline index & range & Pollution degree \\
\hline & $\mathrm{Pi} \leq 1$ & Uncontaminated \\
Single & $1<\mathrm{Pi} \leq 2$ & Light pollution \\
factor & $2<\mathrm{Pi} \leq 3$ & Moderately polluted \\
index & $\mathrm{Pi}>3$ & Heavy pollution \\
\hline
\end{tabular}

According to the fact that shallow groundwater in Xiaoxian County is mainly used for industrial, agricultural and concentrated drinking water sources, the Class III water quality standard limit in the Groundwater Quality Standard (GB/T14848-2017) is used as the evaluation standard for the single-factor pollution index. At the same time, considering that the main crop type in Xiaoxian County is wheat, in order to investigate the use value of shallow groundwater as irrigation water, the standard limit for dry farming in the "Farmland Irrigation Water Quality Standard" (GB5084-2005) is adopted. As the "Farmland Irrigation Water Quality Standard" (GB5084-2005) lacks the standard limit of Ni in the dry farming standard, the analysis shall refer to the $\mathrm{Ni}$ in the category III water quality standard in the "Groundwater Quality Standard" (GB/T14848-2017) Limit.

\subsubsection{Nemerow Comprehensive Pollution Index Method}

The most commonly used method in the calculation of the comprehensive pollution index is the Nemerow comprehensive pollution index method, which has the advantages of convenient calculation, simple and clear results, and reasonable and reliable methods. More importantly, it combines the average value of the singlefactor pollution index with The maximum value is taken into consideration, and the heavy metal pollution of the sampling point is comprehensively evaluated. Compared with the single-factor pollution index method, it can reflect the comprehensive water quality more simply and is convenient for statistical analysis and utilization ${ }^{[8,9]}$, but the pollution factor is too prominent. Treat things equally. The specific expression is shown in formula (2).

$$
\mathrm{P}_{\mathrm{N}}=\sqrt{\frac{\left(\mathrm{C}_{\mathrm{i}} / \mathrm{S}_{\mathrm{i}}\right)^{2} \text { max }+\left(\mathrm{C}_{\mathrm{i}} / \mathrm{S}_{\mathrm{i}}\right)^{2} \mathrm{ave}}{2}}
$$

$\mathrm{P}_{\mathrm{N}}$ represents the comprehensive pollution index of the shallow groundwater at the sampling point. See Table 2 for specific classification standards; $\left(\mathrm{C}_{\mathrm{i}} / \mathrm{S}_{\mathrm{i}}\right)$ ave represents the average value of the single factor index of heavy metal pollutants; $\left(\mathrm{C}_{\mathrm{i}} / \mathrm{S}_{\mathrm{i}}\right)$ max represents the maximum value of the single factor index of heavy metal pollutants. 
Table 2. Nemerow Comprehensive Pollution Index Classification Standard

\begin{tabular}{cccccc}
\hline level & excellent & better & good & poor & $\begin{array}{c}\text { very } \\
\text { bad }\end{array}$ \\
\hline $\mathrm{P}_{\mathrm{N}}$ & $<0.80$ & $0.80 \sim 2.50$ & $2.50 \sim 4.25$ & $4.25 \sim 7.20$ & $>7.20$ \\
\hline
\end{tabular}

\subsubsection{Health risk assessment}

Health risk assessment is based on risk as an indicator, and quantitatively describes a potential risk of environmental pollution to human health ${ }^{[10]}$. In this evaluation, HQ (hazard quotient index) and Risk (carcinogenic risk index) were used to evaluate the health risks of five heavy metal elements and two heavy metal elements, which are chemical carcinogens, $\mathrm{Cr}$ and $\mathrm{Cd}$, to conduct carcinogenic risk evaluation. The chemical carcinogen $\mathrm{Cr}$ can damage the gastrointestinal tract and affect the normal circulatory metabolism in the body after being eaten into the human body. Therefore, the concentration level of $\mathrm{Cr}$ in the water in the study area should be paid attention to. In addition, when the chemical carcinogen $\mathrm{Cd}$ enters the human body with a concentration exceeding the acceptable range, it may cause chronic poisoning, cause damage to the human kidney function, and then affect the normal physiological metabolism of the human body. Therefore, although the concentration of $\mathrm{Cd}$ in the study area is low, it is due to the health of the human body. Harmfulness should also be paid attention to in water environmental protection.

1) The hazard quotient index HQ is calculated as formula (3).

$$
\mathrm{HQ}=\mathrm{CDI} / \mathrm{RfD} \quad \mathrm{CDI}=\mathrm{c} \cdot \mathrm{DI} / \mathrm{BW}
$$

CDI is the average chronic daily exposure, c represents the actual measured concentration of heavy metals, DI represents the daily intake dose, using $2 \mathrm{~L} \cdot \mathrm{d}^{-}$ ${ }^{1[11]}$; BW is the average weight of Xiaoxian County adults, using $60 \mathrm{~kg}$; RfD is The doses of oral toxic substances and the RfD values of 5 heavy metals ${ }^{[12]}$ are shown in Table 3. HQ's health risk evaluation grade ${ }^{[13]}$ is shown in Table 4.

Table 3. RfD values of 5 heavy metals Unit: $\mathrm{mg} \cdot(\mathrm{kg} \cdot \mathrm{d})^{-1}$

\begin{tabular}{cc}
\hline element & RfD value \\
\hline $\mathrm{Cr}$ & 0.0015 \\
$\mathrm{Cu}$ & 0.037 \\
\hline
\end{tabular}

\begin{tabular}{cc}
\hline $\mathrm{Zn}$ & 0.3 \\
$\mathrm{Cd}$ & 0.0005 \\
$\mathrm{Ni}$ & 0.02 \\
\hline
\end{tabular}

Table 4. HQ's health risk assessment grade

\begin{tabular}{ccc}
\hline index & range & Degree of risk \\
\hline & $\mathrm{HQ} \leq 1$ & no risk \\
HQ & $1<\mathrm{HQ} \leq 5$ & low risk \\
& $5<\mathrm{HQ} \leq 10$ & medium risk \\
& $\mathrm{HQ}>10$ & high risk \\
\hline
\end{tabular}

2) The carcinogenic risk index Risk is used to evaluate the health risks of carcinogens and is calculated as formula (4).

$$
\text { Risk }=\mathrm{CDI} / \mathrm{SF}
$$

SF represents the cancer slope factor, unit: $\mathrm{mg} \cdot(\mathrm{kg} \cdot \mathrm{d})^{-1}$. Among the five heavy metals, $\mathrm{Cd}$ and $\mathrm{Cr}$ are carcinogens recognized by the International Agency for Research on Cancer ${ }^{[14]}$. The cancer slope factors (SF) of heavy metal pollution factors $\mathrm{Cd}$ and $\mathrm{Cr}$ are $0.5 \mathrm{mg} \cdot(\mathrm{kg} \cdot \mathrm{d})^{-1}$ and $15 \mathrm{mg} \cdot(\mathrm{kg} \cdot \mathrm{d})^{-1}$, respectively. USEPA believes that the risk of carcinogenic risk index is $1 \times 10^{-4}$ as the limit. When $1 \times 10^{-6}<$ Risk $\leq 1 \times 10^{-4}$, there is no risk of cancer; when Risk $>1 \times 10^{-4}$, it means there is a risk of cancer.

\section{Results and Discussion}

\subsection{Analysis of the characteristics of heavy metal content}

The content of heavy metals in shallow groundwater of farmland in Xiaoxian County is shown in Table 5. Comparing with the water quality standards of Class III water in the "Groundwater Quality Standards" (GB/T14848-2017) and comparing with the water quality standards of dry farming in the "Farmland Irrigation Water Quality Standards" (GB5084-2005), the conclusions reached are consistent, 69 Sampling points showed that the average concentration of heavy metals $\mathrm{Cr}$ and $\mathrm{Ni}$ exceeded the standard value, which was beyond the standard. The average content of the other three heavy metals did not exceed the standard value. There were 10 sampling points where the heavy metal element content exceeded the standard.

Table 5. Heavy metal content Unit: $\mu \mathrm{g} \cdot \mathrm{L}^{-1}$

\begin{tabular}{cccccc}
\hline element & Max & Minimum & $\begin{array}{c}\text { Class III standard in } \\
\text { value }\end{array}$ & $\begin{array}{c}\text { Standard for dry farming in } \\
\text { "Groundwater Quality } \\
\text { Standard" (GB/T14848- } \\
\text { "Farmland Irrigation Water } \\
\text { Quality Standard" } \\
\text { (GB5084-2005) }\end{array}$ \\
\hline $\mathrm{Cr}$ & 268.78 & 1.27 & 59.8805 & 50 & 100 \\
$\mathrm{Zn}$ & 266.1 & 0.45 & 52.085 & 1000 & 2000 \\
$\mathrm{Cu}$ & 29.98 & 1.77 & 8.6995 & 1000 & 1000 \\
$\mathrm{Cd}$ & 21.54 & 0.1 & 3.186 & 5 & 10 \\
$\mathrm{Ni}$ & 252.85 & 0.9 & 40.6 & 20 & 20 \\
\hline
\end{tabular}




\subsection{Comprehensive evaluation}

\subsubsection{Analysis of evaluation results of single factor pollution index method}

The water quality standard limits of Class III water in the "Groundwater Quality Standards" (GB/T14848-2017) and the dry farming standard limits in the "Farmland Irrigation Water Quality Standards" (GB5084-2005) are used as reference limits, using single factor The pollution index calculation formula calculates the pollution index value of heavy metals in the shallow groundwater of farmland in Xiaoxian County. The evaluation results are shown in Table 6 .

It can be seen that the water quality standard limit of Class III water in the "Groundwater Quality Standard" (GB/T14848-2017) is used as the reference limit for evaluation. The single factor average index of heavy metal $\mathrm{Cr}$ is 1.198 , which belongs to light pollution; the single factor of heavy metal $\mathrm{Zn}$ The average factor index is $0.052<1$, the pollution degree is non-polluted; the single factor average index of heavy metal $\mathrm{Cu}$ is $0.0087<1$, and the pollution degree is non-polluted; the single factor average index of heavy metal $\mathrm{Cd}$ is 0.637 , which is non-polluted; the single factor of heavy metal $\mathrm{Ni}$ The average of the factor index is 2.03 , between $2-3$ is considered moderate pollution.

The standard limit for dry farming in the "Farmland Irrigation Water Quality Standard" (GB5084-2005) is used as the reference limit for evaluation. The single factor average indexes of heavy metals $\mathrm{Cr}, \mathrm{Zn}, \mathrm{Cu}, \mathrm{Cd}$ and $\mathrm{Ni}$ are $0.599,0.026,0.0087,0.3186$, and 2.03 respectively. There are 4 kinds of heavy metal pollution degrees all belong to non-polluted.

It can be seen from Table 6 that the pollution degree of various metal elements is $\mathrm{Ni}>\mathrm{Cr}>\mathrm{Cd}>\mathrm{Zn}>\mathrm{Cu}$. Among them, the heavy metal $\mathrm{Cr}$ has the most over-standard points, and the number of samples exceeds the standard rate of $40 \%$; the second is $\mathrm{Ni}$, which The number of samples exceeded the standard rate of $35 \%$; the number of samples of $\mathrm{Cd}$ accounted for $10 \%$ of the number of samples; $\mathrm{Zn}$ and $\mathrm{Cu}$ did not exceed the number of samples. Using two different standards as the reference limit, the calculated single factor pollution index of each heavy metal has the same over-standard point and the same over-standard rate.

Table 6. Evaluation results of single factor pollution index

\begin{tabular}{ccccccc}
\hline \multicolumn{2}{c}{ Take groundwater quality standards as reference objects } & \multicolumn{2}{c}{ Take farmland irrigation water quality standards as } \\
reference objects
\end{tabular}

\subsubsection{Analysis of Nemerow Comprehensive Pollution Index Evaluation Results}

Because the "Farmland Irrigation Water Quality Standard" (GB5084-2005) lacks the standard limit of the heavy metal $\mathrm{Ni}$ in the dry farming standard limit, and the concentration of $\mathrm{Cr}, \mathrm{Zn}$ and $\mathrm{Cr}$ in the "Groundwater Quality Standard" (GB/T14848-2017) The limit value is relatively lower, the water quality standard requirements are higher, and the calculated single-factor pollution index value is also higher. Therefore, the more stringent "Groundwater Quality Standard" (GB /T14848-2017) The heavy metal concentration limit in the water quality standard of Class III water is used as the reference object for the shallow groundwater of farmland in Xiaoxian County, to look at the current situation of heavy metal pollution in the shallow groundwater of farmland in Xiaoxian County from a higher perspective, in order to better understand the regional water environment Provide support. See Table 7 for specific evaluation results. It can be seen from Table 7 that the pollution degree of the five heavy metal elements in the study area is $\mathrm{Ni}>\mathrm{Cr}>\mathrm{Cd}>\mathrm{Zn}>\mathrm{Cu}$. The Nemerow comprehensive pollution index of heavy metals $\mathrm{Cr}, \mathrm{Zn}, \mathrm{Cu}, \mathrm{Cd}$ and $\mathrm{Ni}$ are 5.507, 0.271, 0.0312, 4.35 and 12.8 respectively; the evaluation grades are respectively $\mathrm{Cr}$ and $\mathrm{Cd}$, and the good ones are $\mathrm{Cu}$ and $\mathrm{Zn}$. Heavy metals The rating of $\mathrm{Ni}$ is extremely poor.

The Nemerow comprehensive pollution index of each sampling point ranges from 0.251 to 9.325 , with an average value of 1.934. Among them, the number of samples with extremely poor pollution level accounts for $5 \%$, and the number of samples with excellent pollution levels accounts for 55\%, which is in good condition The number of samples with better pollution level accounted for $15 \%$, and the number of samples with poor pollution level accounted for $10 \%$. In general, most of the heavy metals in the shallow groundwater of the farmland in the study area are still within the safe range. The comprehensive pollution index of Nemerow for heavy 
metals in the shallow groundwater area of farmland in Xiaoxian County is 9.523, and the pollution level is extremely poor.

Table 7. Evaluation results of heavy metal pollution factors

\begin{tabular}{cccccc}
\hline element & $\mathrm{Cr}$ & $\mathrm{Zn}$ & $\mathrm{Cu}$ & $\mathrm{Cd}$ & $\mathrm{Ni}$ \\
\hline $\mathrm{P}_{\mathrm{N}}$ & 5.507 & 0.271 & 0.031 & 4.354 & 12.80
\end{tabular}

Evaluation grade Poor excellent excellent Poor very bad

\subsection{Health Risk Assessment of Heavy Metals}

The HQ values of the five heavy metal hazard quotient indexes studied in this paper are shown in Table 8. The results show that the health risk index $\mathrm{HQ}$ of $\mathrm{Cr}$ ranges from 0.0028 to 0.5973 , with an average value of 0.1364 ; the health risk index HQ of $\mathrm{Zn}$ ranges from 0.00005 to 0.0296 , with an average value of 0.0058 ; the health risk index of $\mathrm{Cu}$ ranges from 0.0016 to 0.0270 , with an average value. The value is 0.0078 ; Cd's health risk index HQ ranges from 0.0067 to 1.436 , with an average value of 0.2124 ; Ni's health risk index HQ ranges from 0.0015 to 0.4214 , with an average value of 0.0677 . The average value of the five heavy metal hazard quotient indexes HQ is smaller. The big order is $\mathrm{Zn}<\mathrm{Cu}<\mathrm{Ni}<\mathrm{Cr}<\mathrm{Cd}$. The overall heavy metal content of the study area is at a risk-free health level. Only the heavy metal hazard quotient index values of heavy metals $\mathrm{Cd}$ and $\mathrm{Cr}$ show that two sampling points are at a low-risk health level.

The carcinogens $\mathrm{Cd}$ and $\mathrm{Cr}$ among the five heavy metals are evaluated for their health risks using the carcinogenic risk index Risk. The carcinogenic risk index Risk of $\mathrm{Cd}$ and $\mathrm{Cr}$ is shown in Table 9. Among the 69 sampling points, 19 of the $\mathrm{Cr}$ carcinogenic risk index (Risk) were greater than 10-4, accounting for $27.5 \%$, indicating that the heavy metal $\mathrm{Cr}$ in the shallow groundwater of the farmland in Xiaoxian County has a greater carcinogenic risk. The carcinogenic risk index (Risk) of $\mathrm{Cd}$ in all sampling points is less than 10-4, indicating that there is no carcinogenic risk caused by the chemical carcinogen $\mathrm{Cd}$ in the shallow groundwater of farmland in Xiaoxian County. In summary, the chemical carcinogen $\mathrm{Cr}$ is the main source of heavy metal health risks in the shallow groundwater of Xiaoxian County farmland, followed by $\mathrm{Cd}$; other heavy metal elements other than $\mathrm{Cd}$ and $\mathrm{Cr}$ chemical carcinogens have less health risks, so the chemical Carcinogens $\mathrm{Cr}$ and $\mathrm{Cd}$ should attract special attention.

Table 8. Calculation results of the hazard quotient index HQ

\begin{tabular}{cccccc}
\hline$H Q$ & $\mathrm{Cr}$ & $\mathrm{Zn}$ & $\mathrm{Cu}$ & $\mathrm{Cd}$ & $\mathrm{Ni}$ \\
\hline Max & 0.5973 & 0.0296 & 0.0270 & 1.436 & 0.4214 \\
Minimum & 0.0028 & 0.00005 & 0.0016 & 0.0067 & 0.0015 \\
average value & 0.1364 & 0.0058 & 0.0078 & 0.2124 & 0.0677 \\
Number of samples with health risks & 2 & 0 & 0 & 2 & 0 \\
\hline
\end{tabular}

Table 9. Risk analysis of the carcinogenic risk index of $\mathrm{Cd}$ and $\mathrm{Cr}$

\begin{tabular}{ccc}
\hline item & $\mathrm{Cr}$ & $\mathrm{Cd}$ \\
\hline Max & $1.79 \times 10^{-2}$ & $4.79 \times 10^{-5}$ \\
Minimum & $8.47 \times 10^{-5}$ & $2.22 \times 10^{-7}$ \\
average value & $3.9 \times 10^{-3}$ & $7.08 \times 10^{-6}$ \\
Number of samples at risk of causing cancer & 19 & 0 \\
\hline
\end{tabular}

\section{Conclusions}

The average value of heavy metal content in the shallow groundwater of Xiaoxian County farmland is compared with the reference standard. It can be seen that the content of heavy metals $\mathrm{Cr}$ and $\mathrm{Ni}$ exceeds the standard, and the average content of the three heavy metals of $\mathrm{Cu}$, $\mathrm{Cd}$ and $\mathrm{Zn}$ does not exceed the standard value. The evaluation results of the single factor index method show that the heavy metal $\mathrm{Cr}$ has the largest number of overstandard samples, followed by $\mathrm{Ni}$, followed by $\mathrm{Cd}$; heavy metals $\mathrm{Zn}$ and $\mathrm{Cu}$ have no over-standard points.

The calculation result of Nemerow comprehensive pollution index method shows that the pollution degree of 5 heavy metal elements in the shallow groundwater of farmland in Xiaoxian County is $\mathrm{Ni}>\mathrm{Cr}>\mathrm{Cd}>\mathrm{Zn}>\mathrm{Cu}$. The Nemerow comprehensive pollution index of heavy metal $\mathrm{Ni}$ is considered to be extremely poor and should be paid more attention. The Nemerow comprehensive pollution index ranged from 0.251 to 9.325 at each sampling point, with an average value of 1.934 . The number of samples belonging to good water quality is the largest; the Nemerow comprehensive pollution index in the entire study area is 9.523 , and the pollution level is extremely poor.

$\mathrm{Cr}$, a chemical carcinogen, is the main source of heavy metal health risks. Non-chemical carcinogens such as $\mathrm{Cu}, \mathrm{Zn}$, and $\mathrm{Ni}$ have relatively low health risks, and $\mathrm{Cr}$ carcinogen risk in 69 sampling points. The Index (Risk) has 19 samples greater than $10^{-4}$, and $27.5 \%$ of samples have health risks.

\section{Acknowledgments}

This article was funded by the Humanities and Social Sciences Key Project of the Department of Education of 
Anhui Province (SK2020A0528), the Quality Engineering Project (2020szsfkc1024, szxy2020xskc04) and the Key Scientific Research Project of Suzhou University (2017yzd13).

\section{References}

1. Liang Yaya, Yi Xiaojun, Dang Zhi, etc. (2019) Heavy metal pollution status and risk assessment of farmland soil around a lead-zinc tailing pond. Journal of Agricultural Environment Sciences, 38:103-110.

2. Guo Hui, Yu Minda, He Xiaosong, Luo Yueping. (2016) Pollution characteristics of shallow groundwater in typical farmland areas in southern China. Environmental Science, 37: 4680-4689.

3. Fan Junling, Xu Yan, Zhu Lixia. (2016) Study on the characteristics of heavy metals in shallow groundwater in Boai County. Journal of Jiaozuo University, 30: 65-67.

4. He Jiangyi, Zhang Dong, Zhao Zhiqi. (2017) Distribution characteristics and source analysis of heavy metals in groundwater in vegetable growing areas in northern Henan. Environmental Chemistry, 36: $1537-1546$.

5. Sun Jianxiong, Luo Ting, Zhou Feng, etc. (2018) Pollution characteristics and evaluation of heavy metals in surface water in Yancheng coastal area, Jiangsu. Environmental Pollution and Control, 40: 1294-1299.

6. Yang Xuefu, Guan Jianling, Duan Jinming, etc. (2014) The current status of heavy metal pollution in Xi'an section of the Weihe River and its health risk assessment. Bulletin of Soil and Water Conservation, 34: 152-156, 162.

7. Cheng Peng, Li Xuyong. (2017) Water weight metal pollution and health risk assessment in different time and space in Yanghe River Basin. Environmental Engineering Journal, 11: 4513-4519.

8. Xu Bin, Lin Canyao, Mao Xinwei. (2014) Analysis of the applicability of Nemerow water pollution index method in the water quality assessment of Lake Tai. Water Resources Protection, 30: 38-40.

9. Yang Huiwen, Dong Tianming, Wang Liping, etc. (2018) The application of the modified Nemerow pollution index method in the evaluation of river water quality in Guangzhou. Guangdong Chemical Industry, 45: 64-66, 83.

10. Xu Meijuan, Bao Bo, Chen Chunyan, etc. (2018) The current status and health risk assessment of heavy metal pollution in surface waters in Ningbo. Environmental Science, 39: 152-162.

11. Reza R, Singh G. (2010) Assessment of heavy metal contamination and its indexing approach for river water. International Journal of Environment Science and Technology, 7: 785-792.

12. US.EPA. EPA /630 /P-03/001F, (2005) Guidelines for carcinogen risk assessment [S]. Washington,

\section{DC: U.S.EPA.}

13. Khan S, Cao Q, Zheng Y M, et al. (2008) Health risks of heavy metals in contaminated soils and food crops irrigated with wastewater in Beijing, China. Environmental Pollution, 152: 686-692.

14. IARC. (2011) IARC Monographs on the evaluation of carcinogenic risks to humans. IARC Press, Lyon, France: World Health Organization. 